\title{
Relay Feedback Identification based Load Frequency Control and Controller Design
}

\author{
Kunduru Laxmi Pavan Kumar Reddy,", Dola Gobinda Padhan². \\ ${ }^{1}$ EEE Departmemt, Gokaraju Rangaraju Institute of Engineering and Technology, Hyderabad, India, \\ ${ }^{2}$ EEE Departmemt, Gokaraju Rangaraju Institute of Engineering and Technology, Hyderabad, India,
}

\begin{abstract}
The main objective of power system operation and control is to maintain the continuity of supply with required quality and reliability. In power system operation one of the issue is Load frequency control. Generally, the dynamics of the system ( i.e the over all dynamics of governor ,turbine, load and machine) for isolated or inter-connected power system is of higher order. The controller design for a higher order system is a tedious process. In order to over come this difficultly relay feedback identification approach has been adopted. In this approach the higher order system has been reduced to lower order system by the method of IMC-PID tuning control. Robust controller has been design for identified model for single area power system in order to achieve satisfactory closed loop performance. The same concepts have been readily extended to multi area power system.
\end{abstract}

\section{Introduction}

The problem of control the real power output of generating units in response to changes in system frequency and tie-line power inter change with in specified limits is known as load frequency control [1]. The deviation of the frequencies and tie-line power arise because of unpredictable load variations, which occur due to a mismatch between the generated and the demanded power[2]. To ensure the quality of the power supply, a load-frequency control is required to minimize the transient deviations and ensure zero steady-state errors of these two variables[3]. The objective of the control strategy in a power system is to generate and deliver power in an interconnected system as economically and reliably as possible while maintaining the frequency and voltage

within permissible limits [4-5].To maintain stability of system were required best $\&$ simple control method like IMC-PID Tuning, it is most used method in industrial controller in the process of maintain stability of real power by controlling load frequency variation [6-9] .

In this paper relay feedback identification based load frequency control is proposed and design by using IMCPID tuning method (Internal model control is one of the popular tuning method for PID controller). The proposed approach is flexible in the performance and robustness of the closed -loop systems. The proposed control structure has two tuning parameters. The method can be extended to multi - area power systems easily.

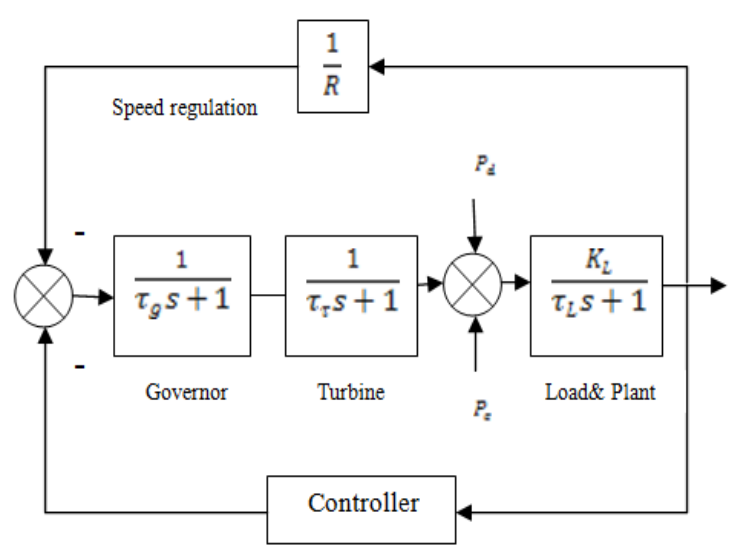

Fig-1: LFC Typical structure.

TABLE-1 NOMENCLATURE

$\Delta \mathrm{f} \quad$ Deviation of frequency $(\mathrm{HZ})$.

$\Delta P_{d} \quad$ Plant or Load disturbance (p.u.MW).

$\Delta \mathrm{P}_{e} \quad$ Power from excitation system (p.u.MW).

$\mathrm{R} \quad$ Speed regulation of the plant (HZ/p.u.MW).

$\Delta P_{G} \quad$ Incremental change in generator output(p.u.MW).

\footnotetext{
* Corresponding author: pavankunduru796@gmail.com
} 


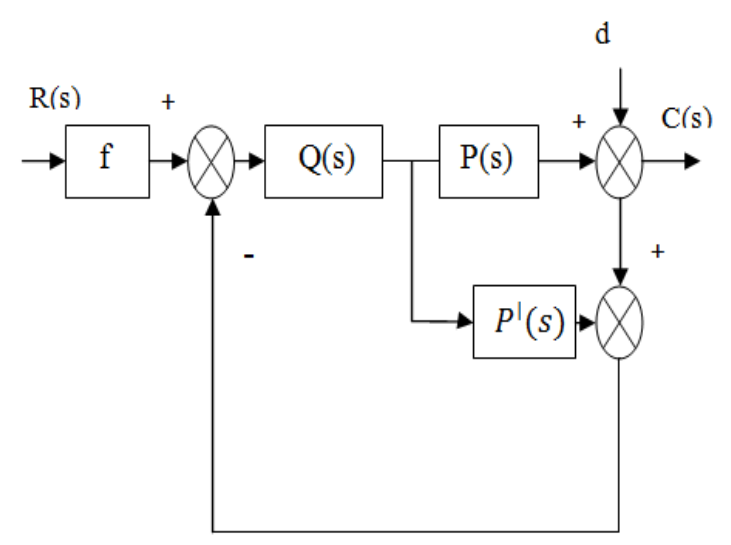

Fig-2: IMC Typical model.

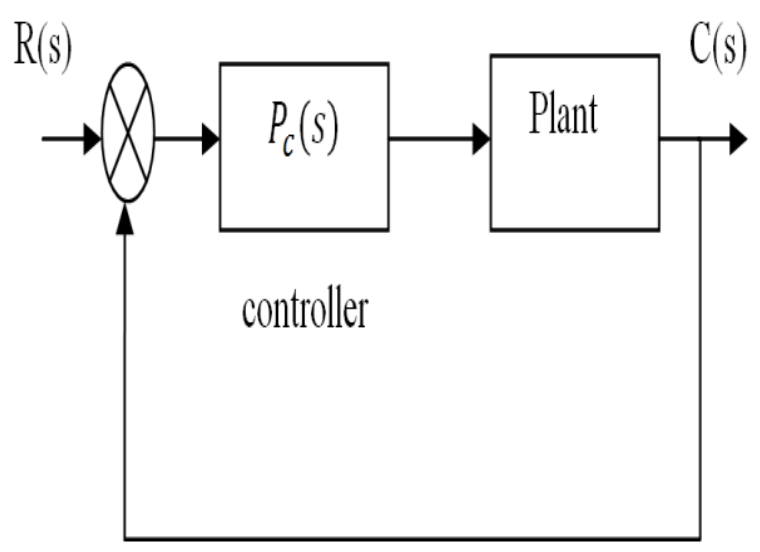

Fig-3: Equivalent block diagram of IMC model.

\section{IMC- DESIGN}

The concept adopt from IMC method for load frequency controller design[2]. It is common control structure used in process control. The IMC structure shown in fig-2, where $\mathrm{P}(\mathrm{s})$ is to be controlled, ${ }^{\mathrm{P}}(s)$ is the plant model, $\mathrm{Q}(\mathrm{s})$ is IMC-controller were Design .

\section{IMC -Model design steps are followed:}

Step-1:

From concept of IMC parameterization the plant model is :

$$
\mathrm{P}^{\prime}(s)=P_{M}(s) P_{A}(s)
$$

$P_{M}$ is the system with all pole's and zero's of system present at left side of S-plane(minimum phase system), $P_{\mathrm{A}}(s)_{\text {is }}$ the system with zero's present at right side of $\mathrm{S}$ plane(non-minimum phase system), $P_{A}(0)=1$.

Step-2:

Design of set-point tuning of IMC -Controller.

$$
\mathrm{Q}(\mathrm{s})=P_{M}^{-1}(\mathrm{~s}) f(\mathrm{~s})
$$

where, $f$ is the filter of IMC model

$$
\mathrm{f}(\mathrm{s})=\frac{\left(\sum_{i=1}^{m} \alpha_{i} s^{i}+1\right)}{(\lambda S+1)^{r}}
$$

Here, $\lambda$ is tuning parameter of IMC-Controller, $r$ is higher degree to get better perform of IMC Controller, is parameter to adjust the unstable pole's $\&$ pole's near to the plant which to control.

Step-3:

To cancel the poles the condition to follows:

$1-\left.Q(S) P^{\mathrm{l}}(s)\right|_{s=P_{1} P_{\mathrm{n} m \mathrm{~m}} P_{m}}=0$

Step-4:

Thus, Total close loop response can be determine.

\section{IMC-PID DESIGN FOR LFC}

1.3.1 IMC-PID design for stable third- order system:

To determine the transfer function of IMC-based PID Controllerfor Third order stable plant,

$$
\begin{gathered}
P^{\mathrm{l}}(s)=P_{g}(s) P_{\tau}(s) P_{L}(s) \\
P^{\mathrm{l}}(s)=\frac{K_{L}}{\left(\tau_{g} s+1\right)\left(\tau_{\tau} s+1\right)\left(\tau_{L} s+1\right)}
\end{gathered}
$$

where,

$$
\begin{array}{ll}
\text { Governor of system } & : P_{g}(s)=\frac{1}{\left(\tau_{g} s+1\right)} \\
\text { Turbine of system } & : P_{\mathrm{L}}(s)=\frac{1}{\left(\tau_{\tau} s+1\right)} \\
\text { Load or Plant of system } & : P_{L}(s)=\frac{1}{\left(\tau_{L} s+1\right)} \\
\text { Time constant of governor } & : \tau_{g} \\
\text { Time constant of turbine } & : \tau_{\tau} \\
\text { Gain of the system } & : \mathrm{K}_{\mathrm{L}}
\end{array}
$$

Step-1:

Solve the IMC controller transfer function, From equation (2)

$$
\mathrm{Q}(\mathrm{s})=\frac{\left(\tau_{g} s+1\right)\left(\tau_{\tau} s+1\right)\left(\tau_{L} s+1\right)}{K_{L}} * \frac{1}{(\lambda s+1)}
$$

Step-2:

Solve the typical feedback controller by using the modification, Thus transfer function is

$$
P_{C}(s)=\frac{Q(s)}{\left(1-P^{\mathrm{l}}(s) Q(s)\right.}
$$

Step-3:

Substituting the $Q(s) \&^{P^{l}}(s)$ transfer function in equation (8) and compare with standard PID Controller transfer function.

Equation(8), become:

$\mathbb{P}_{\mathrm{C}}(s)=\frac{\tau_{g} \tau_{\mathrm{z}} \tau_{\mathrm{L}} s^{2}+\left(\tau_{g} \tau_{\mathrm{z}}+\tau_{\mathrm{z}} \tau_{\mathrm{L}}+\tau_{\mathrm{g}} \tau_{\mathrm{L}}\right) \mathrm{s}^{2}+\left(\tau_{\mathrm{g}}+\tau_{\mathrm{z}}+\tau_{\mathrm{L}}\right) \mathrm{s}+1}{K_{\mathrm{L}} \lambda S}$

Standard PID Controller as: 


$$
P_{C}(s)=K_{c}\left[\frac{\tau_{I} \tau_{D} s^{2}+\tau_{I} s+1}{\tau_{I} s}\right]
$$

Here,

$\tau_{I}$ :Time constant of integral.

$\tau_{D}$ : Time constant of derivative.

$\mathrm{K}_{c}$ : Over all gain of the controller.

By comparing equation(9) \& equation(10) the parameter of IMC-based PID Controller are:

$$
\begin{aligned}
\mathrm{K}_{c} & =\frac{\tau_{\mathrm{g}}+\tau_{\tau}+\tau_{\mathrm{L}}}{K_{L} \lambda} \\
\tau_{\mathrm{I}} & =\tau_{\mathrm{g}}+\tau_{\tau}+\tau_{\mathrm{L}} \\
\tau_{\mathrm{D}} & =\frac{\tau_{\mathrm{g}} \tau_{\tau}+\tau_{\tau} \tau_{\mathrm{L}}+\tau_{\mathrm{g}} \tau_{\mathrm{L}}}{\tau_{\mathrm{g}}+\tau_{\tau}+\tau_{\mathrm{L}}}
\end{aligned}
$$

Step-4:

To maintain robustness of the closed loop system , Adjust the value of " $\lambda$ ", up to the system performance is better \& flexibility.

\section{Numerical Analysis}

We adopt, the numerical value from [2], Consider the power system with non-reheat turbine, the plant parameter are:

$K_{L}=120, \tau_{\mathrm{L}}=20, \tau_{\mathrm{T}}=0.3, \tau_{\mathrm{g}}=0.08, \mathrm{R}=2.4$

The plant model without droop characteristics:

$P^{\mathrm{I}}(s)=\frac{120}{(0.08 s+1)(0.3 s+1)(20 s+1)}$

The LFC IMC Design the $\lambda=0.9$ were adjusted, Then the PID controller.

$K(s)=0.188\left[1+\frac{1}{20.38 s}+0.3740 s\right]$

The plant model with droop characteristics:

$\mathrm{P}(\mathrm{s})=\frac{250}{s^{3}+15.88 s^{2}+42.46 s+106.2}$

For $\lambda=0.5$, The parameter of PID Controller were change value ,time constant were remain same, Thus new PID controller were:

$\mathrm{K}(\mathrm{s})=0.339\left[1+\frac{1}{20.38 \mathrm{~s}}+0.3740 \mathrm{~s}\right]$

\section{SIMULATION MODEL}

Here, the simulation model consist Excitation system model:

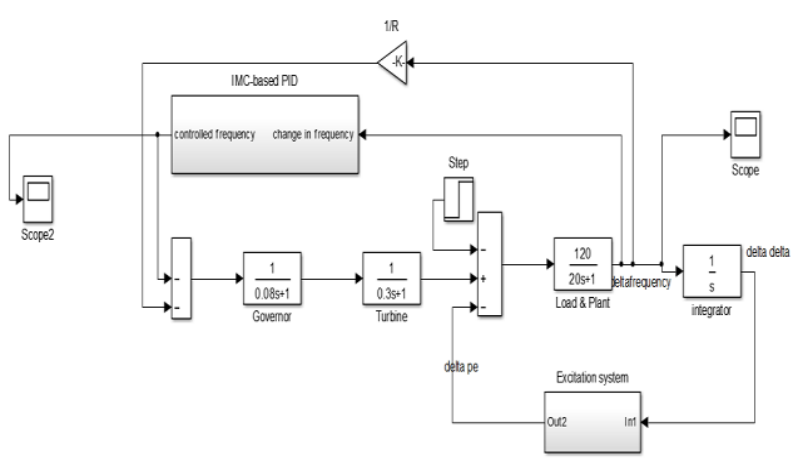

Fig-4: Simulation Block diagram of LFC -IMC based PID model.

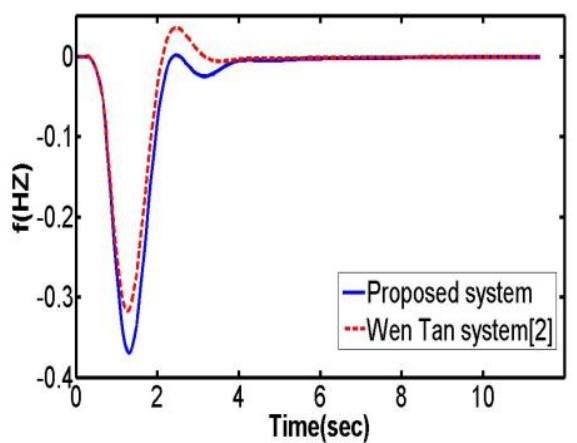

Fig-5: Response of the power system for $\lambda=0.5$, were compare with results of [2].

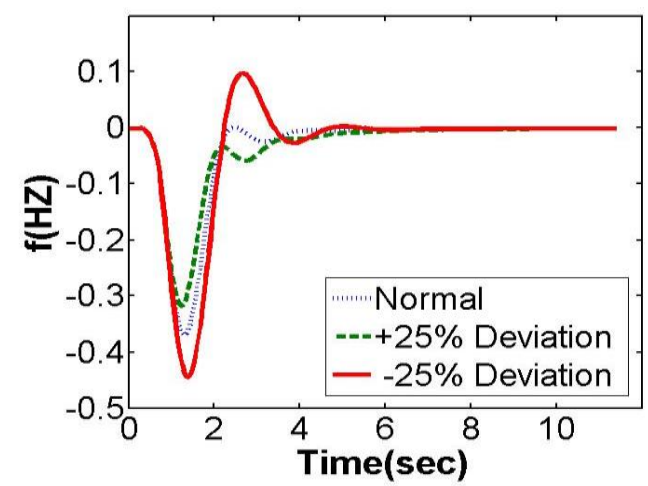

Fig-6: Response of the power system for non-reheat turbine.

From fig-6, the system robustness can be identified for different change in system parameter.

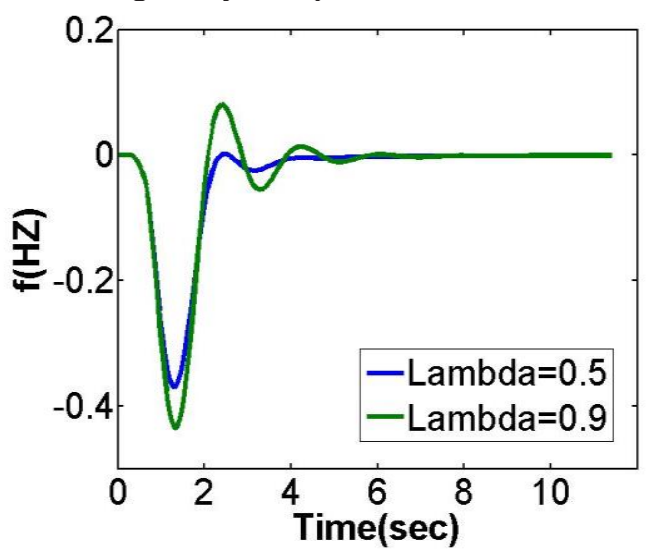

Fig-7: Response of the power system for different value of " $\lambda "$. 
For " $\lambda=0.5$ ", the bode plot of the power system:

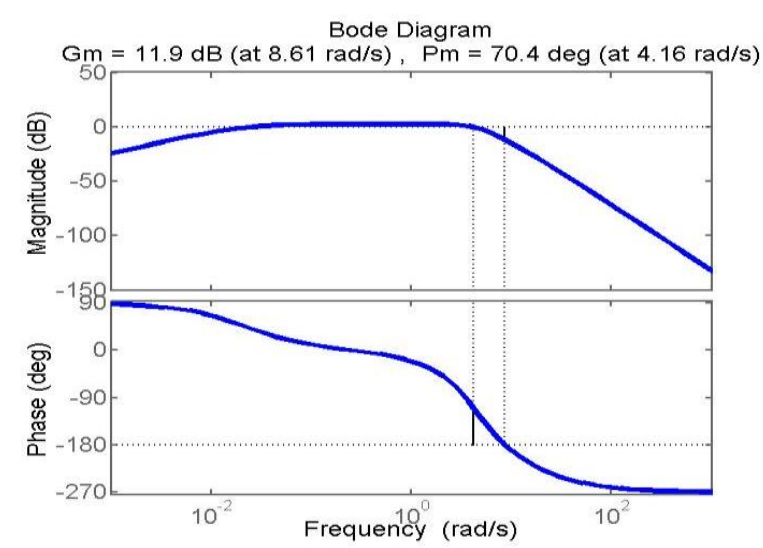

Fig-8: Bode plot of normal system.

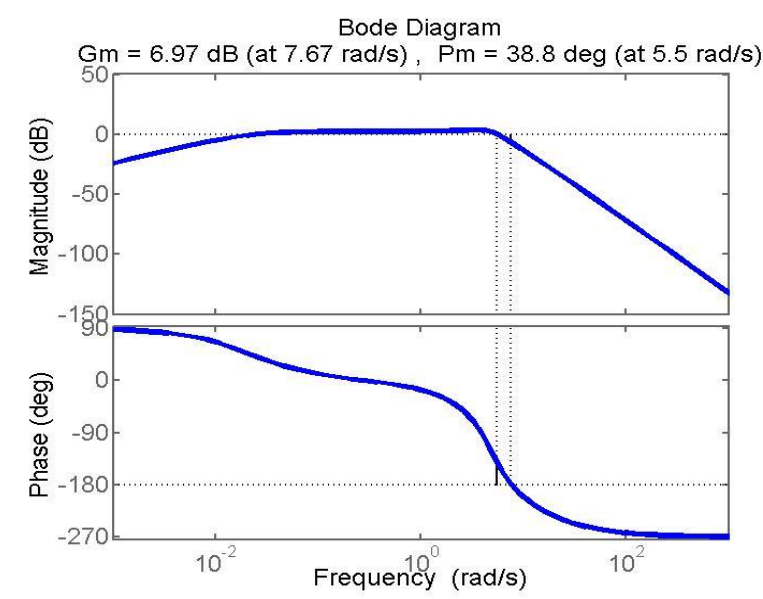

Fig-9: Bode plot of "+25\%" deviation in system.

Bode Diagram

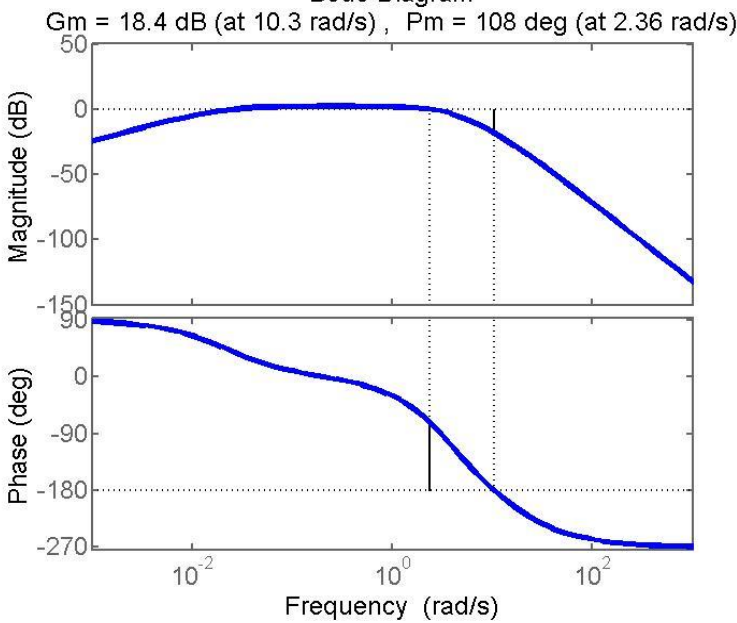

Fig-10: Bode plot of "- 25\%" deviation in system.

Table-2: Variation of Gain \& Phase margin of system

\begin{tabular}{|c|c|c|c|c|}
\hline $\begin{array}{c}\text { S1. } \\
\text { no }\end{array}$ & Margin & Normal & $\begin{array}{c}+25 \% \\
\text { variation in } \\
\text { all } \\
\text { parameters }\end{array}$ & $\begin{array}{c}-25 \% \\
\text { variation } \\
\text { in all } \\
\text { parameter } \\
\text { s }\end{array}$ \\
\hline 1 & Gain & $11.9 \mathrm{db}(\mathrm{at}$ & $6.97 \mathrm{db}(\mathrm{at}$ & $18.4 \mathrm{db}(\mathrm{at}$ \\
$7.67 \mathrm{rad} / \mathrm{s})$ & $10.3 \mathrm{rad} / \mathrm{s})$ \\
\hline
\end{tabular}

\begin{tabular}{|c|c|c|c|c|}
\hline & $(\mathrm{GM})$ & & & \\
\hline 2 & $\begin{array}{c}\text { Phase } \\
\text { margin } \\
(\mathrm{PM})\end{array}$ & $\begin{array}{c}70.4 \mathrm{deg}(\mathrm{at} \\
4.16 \mathrm{rad} / \mathrm{s})\end{array}$ & $\begin{array}{c}38.8 \mathrm{deg}(\mathrm{at} \\
5.5 \mathrm{rad} / \mathrm{s})\end{array}$ & $\begin{array}{c}108 \mathrm{deg}(\mathrm{at} \\
2.36 \mathrm{rad} / \mathrm{s})\end{array}$ \\
\hline
\end{tabular}

\section{Conclusion}

A Relay feedback identification of load frequency control of the power system is addressed in this paper. The controller parameters were tuned with IMC approach setting to improve performance of system stability and robustness. The beauty of the tuning method is that the controller parameters are expressed in terms of plant parameters. Further, the proposed technique is flexible and can easily applied to a multi area power system.

\section{References}

1. P.Kundur, Power System Stability and control.newyork:McGraw-Hill,1994.

2. Wen Tan, "Unified Tuning of PID Load frequency controller for Power System Via IMC",IEEE Transactions on Power Systems, VOL.25, 1,FEBRUARY 2010.

3. D. G. Padhan and S. Majhi, A New Control Scheme for PID Load Frequency Controller of Singlearea and Multi-area Power Systems, ISA Transactions, 52, 242-251, 2013.

4. D. G. Padhan and S. Majhi, Synthesis of PID tuning for a new parallel cascade control structure, IFAC Proceeding Volumes, 45(3), 566-571, 2012.

5. Ibraheem, Prabhat Kumar, and Dwarka P. Kothari, Recent Philosophies of Automatic Generation Control Strategies in Power Systems, IEEE Transactions on Power Systems, Vol. 20, No. 1, February 2005.

6. Muhammad Masum Jujuly,"Analytical Design of PID Controller for Enhanced Disturbance Rejection of Processes without Time Delay", Thesis of Graduate School of Yeungnamuniversity,June 2010.

7. Raghunath Bajarangbali, Somanath Majhi, Saurabh Pandey, "Identification of FOPDT and SOPDT process dynamics Transactions, Vol 53, Issue 4, pp. 1223-1231, July 2014.

8. Raghunath Bajarangbali, Somanath Majhi "Identification of non-minimum phase processes with time delay in the presence of measurementnoise" ISA Transactions, Vol 57, pp. 245-253, July 2015.

9. S. Majhi, Relay based identification of processes with time delay, Journal of process control, 17, 93101,2007. 